\title{
Modelo de previsão fluviométrica para o rio Xingu na cidade de Altamira - PA
}

\author{
Cleber Assis dos SANTOS'; Aline Maria Meiguins de LIMA²; Edivaldo Afonso de Oliveira SERRÃO; Monique \\ Helen Cravo Soares FARIAS4; Romero Thiago Sobrinho WANZELER ${ }^{5}$; Ivinny Barros de ARAUJO2 \\ $\triangle$ cleber_ufpa@yahoo.com.br \\ 1. Universidade Federal de Viçosa, Avenida Peter Henry Rolfs s/n, Minas Gerais, Brasil. \\ 2. Universidade Federal do Pará, Rua Augusto Corrêa l, Pará, Brasil. \\ 3. Universidade Federal de Campina Grande, Rua Aprigio Veloso 882, Paraíba, Brasil. \\ 4. Universidade do Estado do Pará, Trav. Doutor Enéas Pinheiro 1486/1487 - 1828/1829, Pará, Brasil. \\ 5. Instituto Nacional de Pesquisas Espaciais, Rodovia Presidente Dutra, s/n, São Paulo, Brasil.
}

\section{Histórico do Artigo:}

Recebido: 26 de julho de 2016

Aceito: 8 de outubro de 2016

Publicado: 22 de dezembro de 2016

Resumo: Na bacia hidrográfica do rio Xingu, destaca-se o município de Altamira - PA, o maior município do mundo. A sede municipal está localizada as margens do rio Xingu e sofre historicamente com eventos extremos de cheias que provocam inundações, causando grandes prejuízos à população que mora no entorno do rio Xingu, desalojando famílias e ocasionando a vulnerabilidade social. 0 objetivo deste trabalho é elaborar um modelo de previsão fluviométrica, para a cidade de Altamira - PA em função da sazonalidade das características hidrológicas da bacia hidrográfica do rio Xingu. Para testar o desempenho do modelo proposto, em relação aos dados de cota medida e estimada foram utilizados o coeficiente de Nash-Sutcliffe e o coeficiente de determinação. 0 modelo proposto neste trabalho, Modelo de Previsão Hidrológica Xingu Altamira, faz a previsão com dois meses de antecedência, da média mensal da cota fluviométrica do rio Xingu em Altamira - PA. Além disso, utilizando a curva chave, encontra a vazão do rio Xingu em Altamira - PA, com base na cota fluviométrica prevista pelo modelo. As medidas de desempenho consideradas na validação do modelo de previsão mostraram bons resultados, com o coeficiente de Nash-Sutcliffe apresentando valor de NS =0,83 e o coeficiente de determinação com valor de $r^{2}=0,86$. Esses modelos são importantíssimos para entender a sazonalidade dos eventos de cheias e estiagem do rio Xingu, sendo fundamentais para poder dar subsídios ao processo de tomada de decisão na cidade de Altamira - PA.

Palavras-chave: Amazônia, Hidrologia, Nível do rio.

\section{Fluviometric forecasting model for Xingu river in Altamira city - PA}

\begin{abstract}
In the Xingu River Basin, stands out the municipality of Altamira - PA, the largest municipality in the world. The municipal office is located on the banks of the Xingu River and historically has suffered with extreme events like floods, causing great damage to the population that lives surrounding the Xingu River, displacing families and causing social vulnerability. This work aims to develop a fluviometric forecasting model for the city of Altamira - PA based on the seasonality of the hydrological characteristics of the Xingu River Basin. To test the performance of the suggested model relative to measured and estimated data quota were used the Nash-Sutcliffe coefficient and the coefficient of determination. The proposed model in this work, the Hydrological Forecasting Model Xingu Altamira, makes forecast two months in advance of the monthly average of fluviometric quota of the Xingu River in Altamira - PA. Furthermore, using the key curve, it is possible to find the Xingu River flow in Altamira - PA, based on fluviometric quota predicted by the model. The performance measures considered in the forecasting model validation showed good results, with the Nash-Sutcliffe coefficient presenting value of NS $=0.83$ and the coefficient of determination equal to $\mathrm{r}^{2}=0.86$. These models are extremely important to understand the seasonality of events of floods and drought of the Xingu River, being fundamental to give subsidies to the decision-making process in the city of Altamira - PA.
\end{abstract}

Keywords: Amazon, Hydrology, River level. 


\title{
Modelo de predicción fluviométrica para el río Xingu en la ciudad de Altamira - PA
}

\begin{abstract}
Resumen: En la cuenca del río Xingu, está el municipio de Altamira - PA, el municipio más grande en el mundo. La sede del distrito se encuentra a orillas del río Xingu e históricamente sufren de inundaciones extremas, causando un gran daño a la población que vive en las proximidades del río Xingu, desplazando a las familias y causando la vulnerabilidad social. El objetivo de este trabajo es desarrollar un modelo de predicción fluviométrica para la ciudad de Altamira - PA debido a la estacionalidad de las características hidrológicas de la cuenca del río Xingu. Para probar el rendimiento del modelo propuesto, en relación con los datos de cuota medida y estimada, fueron utilizados coeficiente de Nash-Sutcliffe y el coeficiente de determinación. El modelo propuesto en este trabajo, el Modelo de Predicción Hidrológica Xingu Altamira, es la previsión de dos meses de antelación del promedio mensual de la cuota fluviométrica del río Xingu, en Altamira - PA. Además, utilizando la curva la curva clave, se encontrar el caudal de Río Xingu, en Altamira - PA basado en la cuota fluviométrica predicho por el modelo. Las medidas de desempeño consideradas en la validación del modelo de previsión mostraron buenos resultados, con el valor de coeficiente de Nash-Sutcliffe con el valor $\mathrm{NS}=0,83$ y coeficiente de determinación del valor de $\mathrm{r}^{2}=0,86$. Estos modelos son extremadamente importantes para comprender la estacionalidad de los eventos de las inundaciones y la sequía del Río Xingu, es fundamental para dar subsidios a los procesos de toma de decisiones en la ciudad de Altamira - PA.

Palabras clave: Amazon, Hidrología, Nivel del río.
\end{abstract}

\section{INTRODUÇÃO}

A bacia hidrográfica do rio Xingu está situada dentro dos estados do Pará e do Mato Grosso e abrange cerca de 509,7 mil km², onde o rio Xingu é o seu principal curso d'água. Representa um dos principais contribuintes da margem direita do rio Amazonas, tendo em torno de $60 \%$ de seu território recoberto por áreas protegidas (unidades de conservação e terras indígenas) (VILLAS-BÔAS et al., 2012). No estado do Pará, compõe junto com as bacias dos rios Tapajós e Tocantins, o conjunto de bacias federais (que pertencem a mais de um Estado) que drenam mais de 50\% do território paraense. Na bacia hidrográfica do rio Xingu, destaca-se 0 município de Altamira - PA, o maior município do mundo com área de 161.445,93km2 e com uma população de 99.075 pessoas de acordo com o IBGE 2010 (FRANC0, 2014). A cidade de Altamira PA, localizada as margens do rio Xingu, sofre historicamente com eventos extremos de cheias que provocam inundações, causando grandes prejuízos à população que mora no entorno do rio Xingu, desalojando famílias e ocasionando a vulnerabilidade social (FRANC0, 2014; MIRANDA NET0, 2014; SILVA et al., 2014). A sazonalidade dos rios, alternando entre períodos de águas altas (cheias) e águas baixas (secas) produz espacialidades distintas no cenário amazônico. A constante circulação de pessoas e bens pelos rios é afetada diretamente por essa sazonalidade, presumindo assim, que as populações que habitam as margens dos rios e que deles dependem para a execução de suas atividades diárias, busquem adaptar-se a estas mudanças (SAMPAI0 et al., 2012). Como exposto por Breda (2008), as populações procuram se fixar às margens dos rios buscando facilidade nos recursos que este proporciona, porém, a ocupação inadequada das 
planícies, pode ter como consequência grandes prejuízos materiais e perdas humanas consideráveis. Segundo Cristo (2002), muitas cidades desenvolveram suas malhas urbanas ao longo dos leitos dos rios colocando em risco a população que periodicamente em consequências de chuvas intensas e concentradas sofre o problema do transbordamento nas margens das drenagens. Com o crescimento desordenado e acelerado das cidades, principalmente na segunda metade do século passado, as áreas de risco considerável, como as várzeas inundáveis, foram ocupadas, trazendo como consequência prejuízos humanos e matérias (TUCCI, 2005).

0 conhecimento acerca da amplitude do transbordamento dos leitos fluviais é extremamente necessário na determinação das áreas de risco (SANDER et al., 2012). Segundo os boletins hidroclimáticos de monitoramento e previsão da SUDAM/UFPA, a cota de alerta do rio Xingu na cidade de Altamira - PA é de $600 \mathrm{~cm}$, geralmente este nível é ultrapassado nos meses de cheia do rio (março, abril e maio). Porém, a irregular e insuficiente rede hidrológica instalada na região Amazônica demanda por mecanismos que permitam otimizar os dados oriundos das estações com mecanismos estatísticos de regionalização. Neste contexto, os modelos hidrológicos são aplicados visando fornecer informações preliminares para construção de reservatórios de água, estudos de impactos das mudanças climáticas em bacias hidrográficas e avaliação sazonal de suprimento e demanda de água para os demais usos múltiplos. A utilização de modelo de previsão para eventos de cheias e estiagens é imprescindível para gerar boletins informativos de alertas e na tomada de decisões em regiões hidrologicamente sensíveis, que segundo Walter et al. (2000), são áreas da bacia hidrográfica que apresentam maior probabilidade de geração de escoamento superficial por saturação. Para Marinho Filho et al. (2012), a utilização de modelos hidrológicos tem sido bastante difundida, tanto na simulação e previsão de cenários hipotéticos para avaliação de impactos, bem como ferramenta na elaboração de projetos hidrológicos ou hidráulicos. Diante do exposto, este trabalho tem por objetivo elaborar um modelo de previsão fluviométrica, para a cidade de Altamira - PA em função da sazonalidade das características hidrológicas da bacia hidrográfica do rio Xingu.

\section{MATERIAL E MÉTODOS}

\section{Local do estudo}

Foram utilizados os dados fluviométricos da estação de Altamira - PA (código 18850000), próximo a foz do rio Xingu. Este rio tem suas nascentes com extensão de $2.271 \mathrm{~km}$ até sua foz, 
no rio Amazonas. Sua bacia tem direção S-N e ocupa uma área total de $509.685 \mathrm{~km}^{2}$, que corresponde a 46 municípios do Mato Grosso e 42 municípios do Pará. Seus principais afluentes são (de montante para jusante) o Suiá-Miçu, Auaiá-Miçu, Comandante Fontoura, Fresco e Bacajá pela margem direita; e Curisevo, Pardo, Iriri e Acarai, pela margem esquerda (Figura 1).

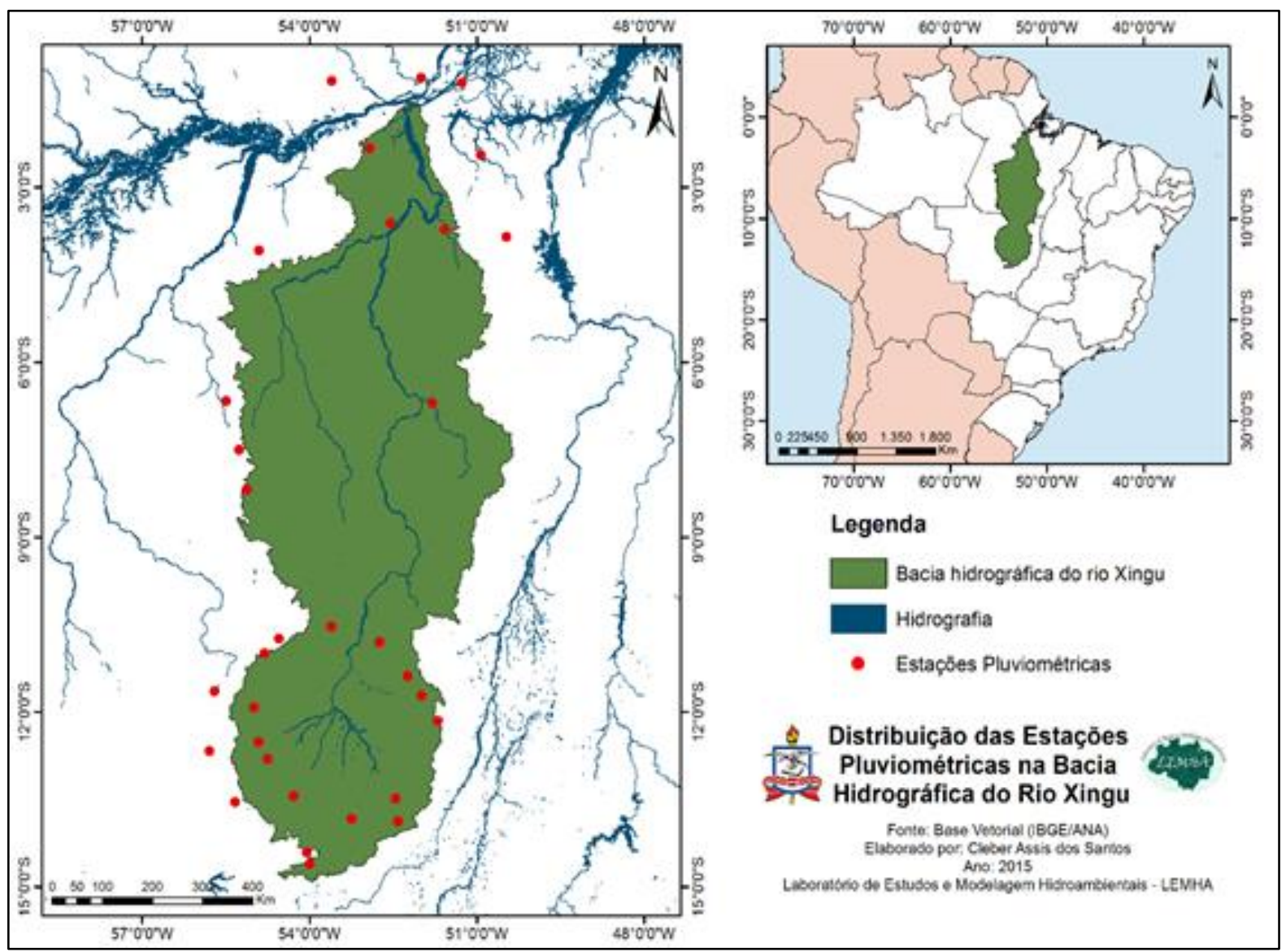

Figura 1. Localização da bacia hidrográfica do rio Xingu e das estações pluviométricas

Fonte: Base vetorial IBGE/ANA, 2015.

\section{Dados utilizados}

Os dados hidrológicos foram obtidos a partir do banco de dados históricos disponibilizados pela Agência Nacional de Águas (ANA), por meio da estação fluviométrica de Altamira - PA (código 18850000), com período de dados utilizados de 1985 a 2013 e médias pluviométricas de 32 estação dentro e no entorno da bacia hidrográfica do rio Xingu com período de 1985 a 2013. 


\section{Análise Estatística}

Por intermédio do software Hidro 1.2 da ANA, foram extraídos os valores fluviométricos e pluviométricos, posteriormente exportados para uma planilha eletrônica.

No teste de desempenho do modelo proposto em relação aos dados de cota medida e estimada, foram utilizados o coeficiente de Nash-Sutcliffe (NS) e o coeficiente de determinação $\left(\mathrm{r}^{2}\right)$. 0 coeficiente de Nash-Sutcliffe varia de $-\infty$ a 1, sendo que quanto mais próximo de 1 melhor é o modelo para representar a massa de dados observados (PEREIRA et al., 2014). 0 coeficiente de NASH é definido como (Equação l):

$$
\begin{aligned}
& N S \\
& =1-\frac{\sum_{i=1}^{n *}\left(E_{m}-E_{S}\right)^{2}}{\sum_{i=1}^{n *}\left(E_{m}-E^{*}\right)^{2}}
\end{aligned}
$$

Onde NS é o coeficiente de Nash-Sutcliffe; Em é o evento monitorado; Es é o evento simulado; E* é a média do evento observado no período da simulação; e n* é o número de eventos.

Outro critério utilizado foi o coeficiente de determinação $\left(\mathrm{r}^{2}\right)$ que segundo Lapponi (2005), o coeficiente de determinação é definido como a relação que mede a proporção da variação total da variável dependente que é explicada pela variação da variável independente (Equação 2). 0 coeficiente de determinação $\left(\mathrm{r}^{2}\right)$ representa a associação linear entre os dados observados e calculados, variando de 0 a 1, com maior valor indicando menor variância do erro (MORIASI et al., 2007).

$$
r^{2}=\frac{\sum_{i=1}^{n}(\tilde{y} i-\bar{y})^{2}}{\sum_{i=1}^{n}(y i-\bar{y})^{2}}
$$

Onde, $\sum_{i=1}^{n}(\tilde{y} i-\bar{y})^{2}$ corresponde à variação explicada; e $\sum_{i=1}^{n}(y i-\bar{y})^{2}$ corresponde à variação não explicada. 


\section{Características do modelo de previsão hidrológica Xingu-Altamira}

0 modelo proposto neste trabalho faz a previsão, com dois meses de antecedência, da média mensal da cota fluviométrica do rio Xingu em Altamira (PA) por meio da média mensal acumulada de precipitação pluviométrica da bacia hidrográfica do rio Xingu.

0 Modelo de Previsão Hidrológica Xingu-Altamira é do tipo concentrado, determinístico e empírico. Segundo Rennó e Soares (2008), o modelo é considerado concentrado quando todas as variáveis de entrada e de saída são representativas de toda área estudada. A utilização da chuva média como variável de entrada neste tipo de modelo é o mesmo que admitir a uniformidade espacial da precipitação representada por estatística pontual (TUCCI, 2005).

0 modelo determinístico é caracterizado pelo fato de uma dada ação de entrada de dados implicar uma mesma resposta (QUINTELA e PORTELA, 2002). Kaiser (2006), admite que o modelo determinístico é adequado para descrever as fases do ciclo hidrológico que não contém componentes aleatórios, logo em uma determinada situação, o modelo produzirá a mesma resposta final. De acordo com Moreira (2005), o modelo empírico é baseado em dados observacionais, são modelos úteis no cotidiano, entretanto são simples já que representa apenas a região onde a relação foi estimada.

No processo de construção, calibração e validação do modelo adotou-se os seguintes passos:

1. Organizar as médias mensais acumuladas de precipitação pluviométrica da bacia hidrográfica do rio Xingu, de 1985 até 2005 (para a construção do modelo) e as médias mensais de cota fluviométrica medida na cidade de Altamira - PA, no mesmo período.

2. Relacionar os dados médios mensais de precipitação e cota medida em Altamira - PA.

3. Calibrar o modelo pelo método de tentativas (MOREIRA, 2005), para obter o melhor coeficiente de determinação $\left(\mathrm{r}^{2}\right)$ e gerar a equação que informe a cota fluviométrica de Altamira - PA em função da precipitação média mensal acumulada da bacia hidrográfica do Xingu.

Validar o modelo com a equação encontrada, utilizando os anos de 2006 até 2013. 


\section{RESULTADOS E DISCUSSÃ0}

\section{Caracterização pluviométrica da bacia hidrográfica do rio Xingu}

De acordo com a série histórica (1985 até 2013) de dados, foi observado que para a bacia do rio Xingu a precipitação anual média é de 1963,5 mm. 0s menores valores de precipitação, encontram-se na região da nascente da bacia hidrográfica e ao Leste (média de 1782,3 mm) e os maiores valores, encontram-se na região da foz e ao 0este (média de 2426,7 mm) (Figura 2).

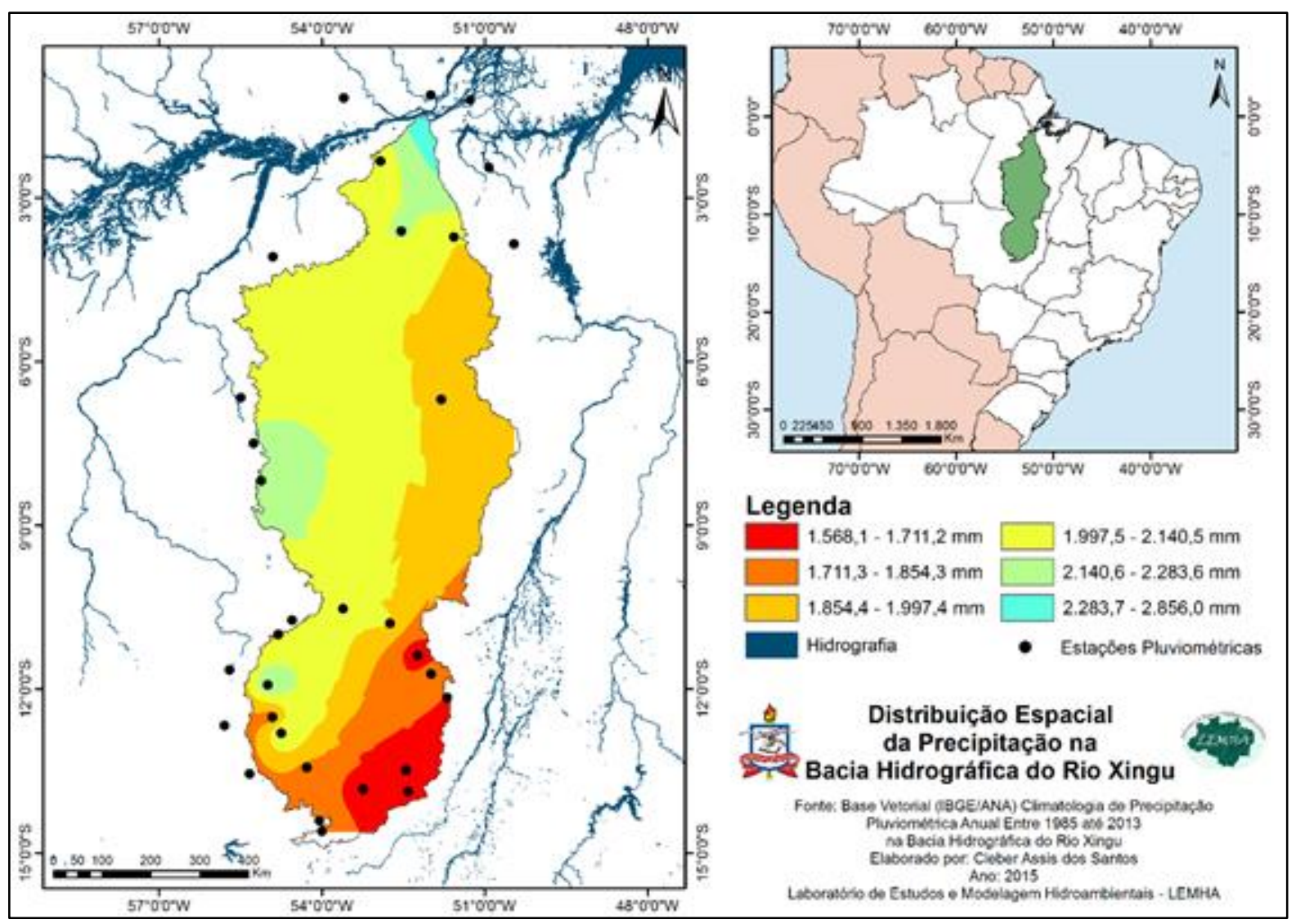

Figura 2. Média anual acumulada da precipitação pluviométrica

Fonte: Base vetorial IBGE/ANA e base hidroclimatologica da ANA, 2015.

Durante o período observado, a precipitação se concentrou entre os meses de novembro a abril $(1541 \mathrm{~mm})$. Por outro lado, entre os meses de maio a outubro, as chuvas ocorrem em menor quantidade, onde a média acumulada nesse período foi de $422 \mathrm{~mm}$ (Figura 3). 


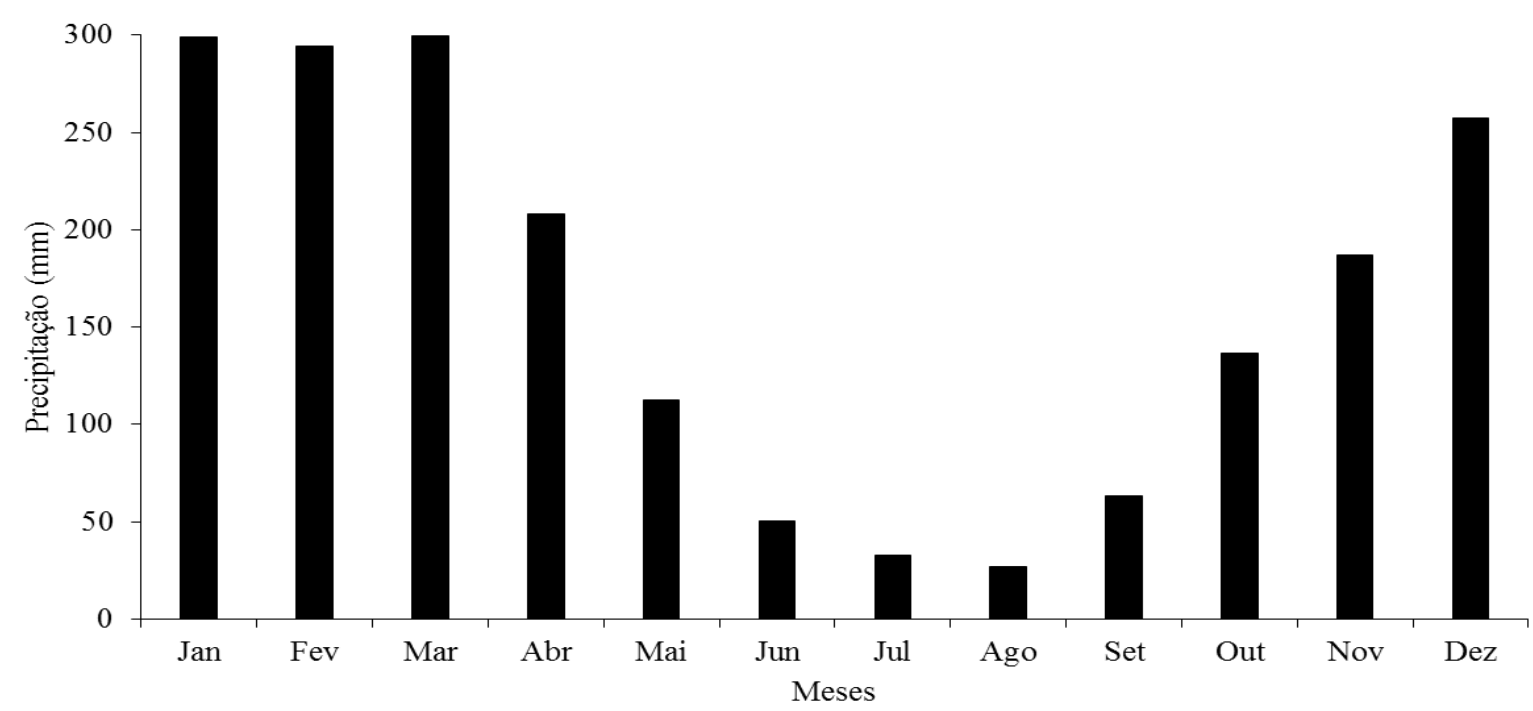

Figura 3. Média mensal acumulada da precipitação pluviométrica

\section{Caracterização fluviométrica do rio Xingu em Altamira - PA}

0 baixo curso do rio Xingu, onde concentram-se os máximos de precipitação, superiores a $2200 \mathrm{~mm} / \mathrm{ano}$, caracterizando esta região com o maior potencial hídrico da bacia, registra valores de vazão superiores a $17000 \mathrm{~m}^{3} / \mathrm{s}$ e cota podendo alcançar até $700 \mathrm{~cm}$ (Figura 4).

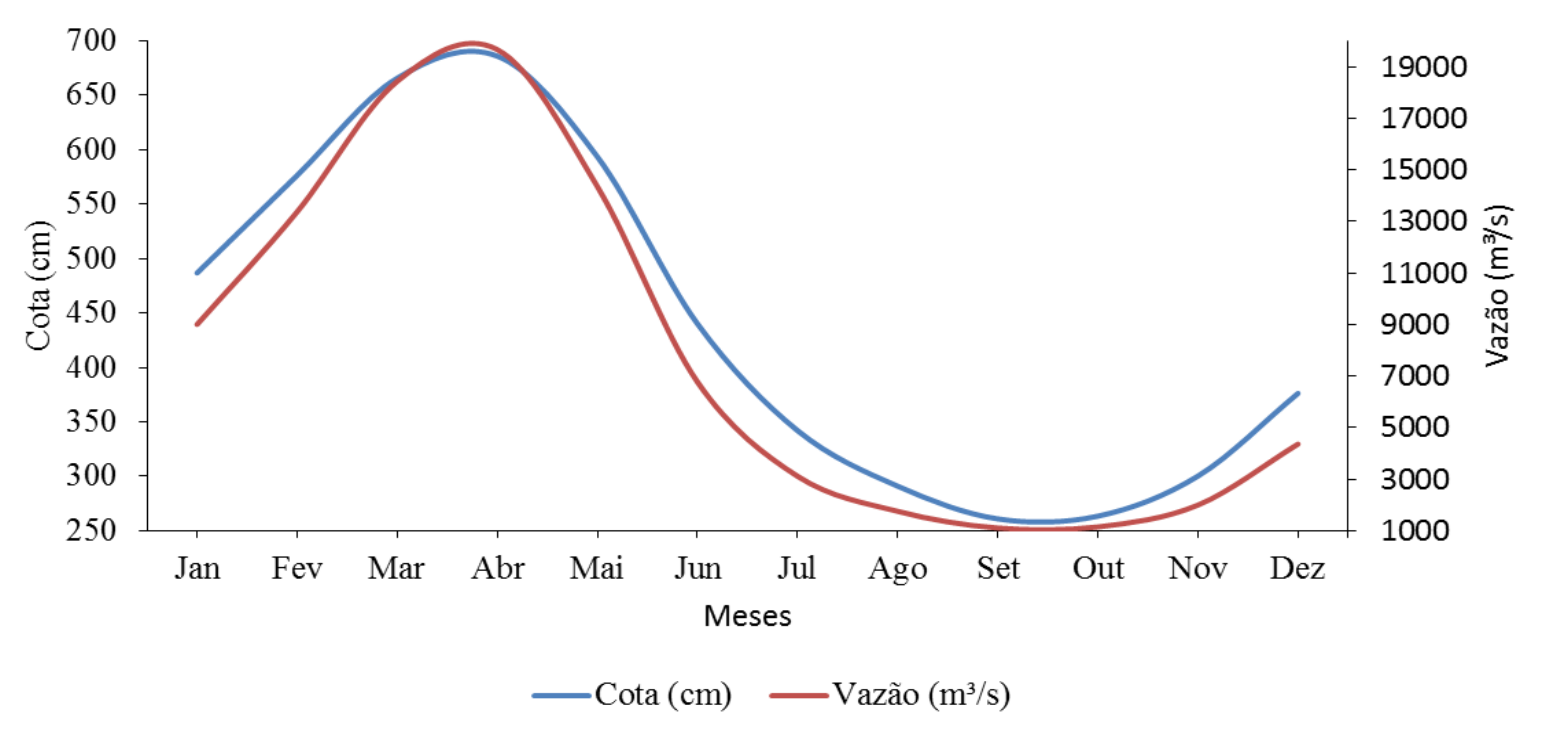

Figura 4. Média mensal da cota e vazão no rio Xingu em Altamira - PA

Esta região tem uma das menores elevações topográficas da bacia (Figura 5), representando uma zona hidrologicamente sensível, principalmente em eventos de cheia do rio Xingu. Segundo Pereira e Teixeira Filho (2009), são consideradas áreas hidrologicamente 
sensíveis, áreas onde existem maior formação de fluxo de água superficial e saturação do solo após um evento de chuva.

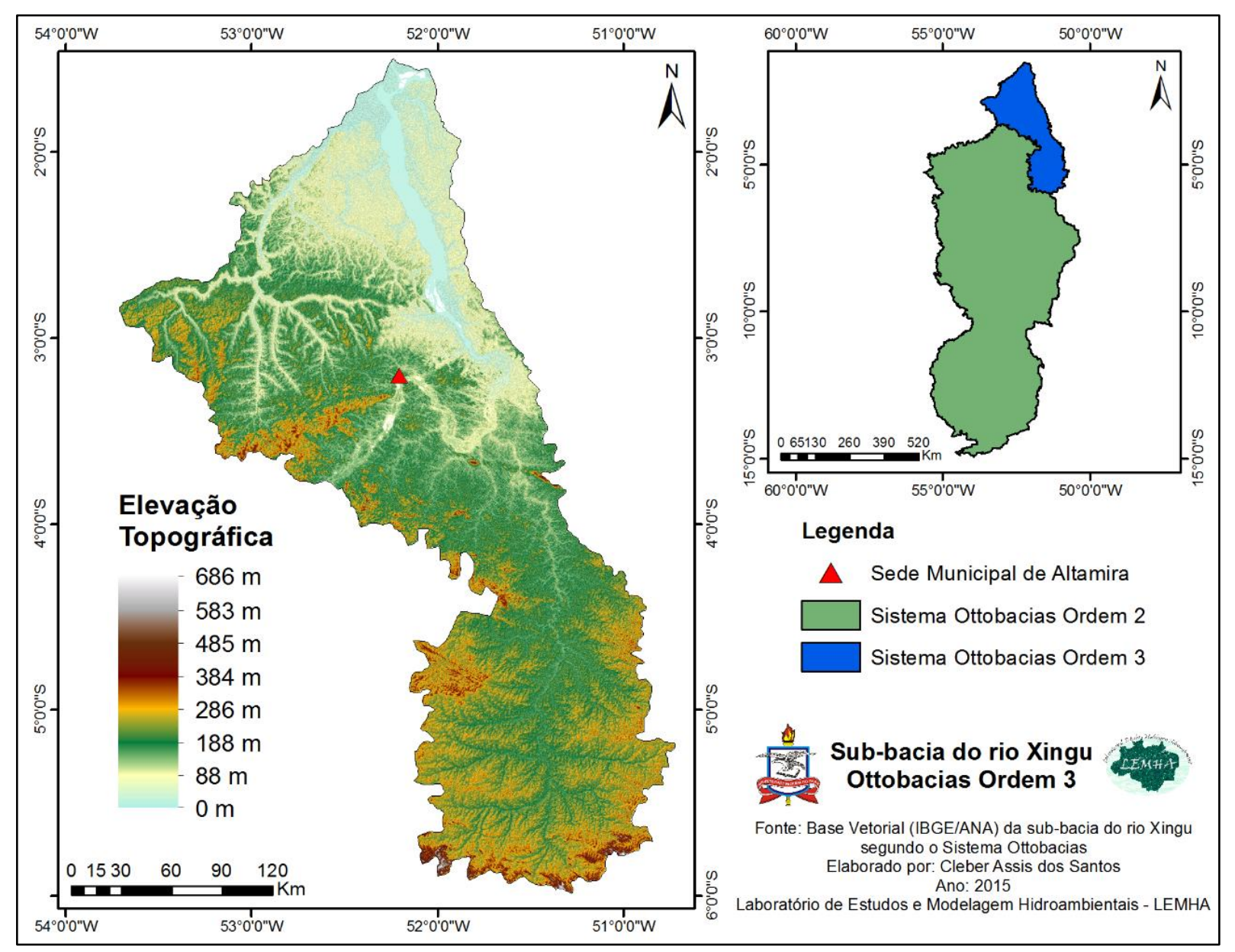

Figura 5. Elevação topográfica da região do baixo curso do rio Xingu

Fonte: Base vetorial IBGE/ANA e topografia do USGS, 2015.

Nesta área, o rio Xingu recebe seu principal afluente, o rio Iriri, os efeitos de retenção dos deflúvios nas baixadas marginais são mais acentuados, ocasionando retardo e atenuação das descargas, na época de enchente, e acréscimos nas vazões na época da vazante. Nas imediações da cidade de Altamira - PA, o rio Xingu sofre uma acentuada deflexão formando a chamada Volta Grande, de grandes corredeiras, com um desnível de $85 \mathrm{~m}$ em 160 km (FRANCO, 2014). 


\section{Modelo de previsão hidrológica Xingu-Altamira}

Após a comparação entre as médias mensais de precipitação pluviométrica acumuladas na bacia hidrográfica do rio Xingu, e as médias mensais de cota fluviométrica do rio Xingu na cidade de Altamira - PA, observou-se que aproximadamente, assim como constatado por Franco (2014), o período de resposta do nível médio mensal do rio Xingu em Altamira - PA, ocorre dois meses após a média mensal de precipitação acumulada na bacia.

Essa relação fica mais evidente em uma análise conjunta da média mensal acumulada da precipitação pluviométrica e da média mensal da cota no rio Xingu em Altamira - PA (Figuras 3 e 4). Podemos observar que a partir do mês de setembro, há o aumento gradual nos níveis pluviométricos na região, em resposta, há o aumento paulatino dos níveis fluviométricos em Altamira - PA. Assim, trabalhando com uma defasagem de dois meses entre as médias mensais de precipitação acumulada na bacia hidrográfica do rio Xingu e a média mensal da cota fluviométrica do rio Xingu na cidade de Altamira - PA, no período de 1985 a 2005, obteve-se (calibrando pelo método de tentativas), através de uma regressão do tipo exponencial (Figura 6), a equação que apresentou o melhor coeficiente de determinação $\left(r^{2}=0,8862\right)$ para a previsão da cota do rio Xingu em Altamira - PA.

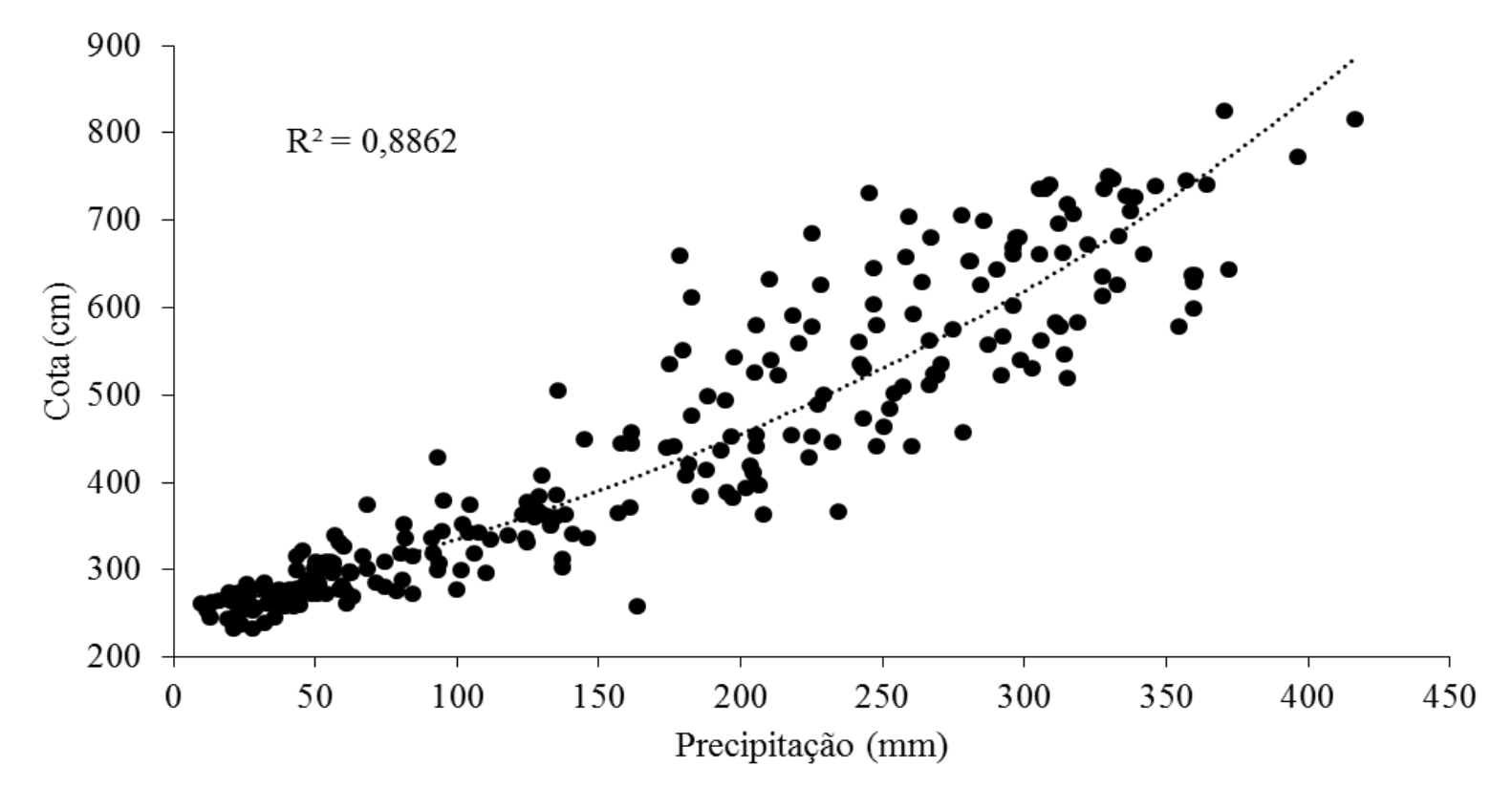

Figura 6. Regressão entre a média mensal da cota fluviométrica e precipitação média mensal acumulada na bacia do Xingu (1985 a 2005), para construção do modelo

Fonte: Própria. 
A equação encontrada (Equação 3), realiza com dois meses de antecedência a previsão da média mensal da cota fluviométrica no rio Xingu, na cidade de Altamira - PA.

$$
Y=246.93 e^{0.0031 x}
$$

Onde, Y representa a previsão da média mensal da cota fluviométrica $(\mathrm{cm})$, com dois meses de antecedência; x representa 0 valor atual da média mensal de precipitação $(\mathrm{mm})$ acumulada dentro da bacia hidrográfica.

Portanto o Modelo de Previsão Hidrológica Xingu-Altamira realiza a previsão da cota média mensal do rio Xingu na cidade de Altamira - PA com dois meses de antecedência em função da média mensal de precipitação acumulada, ou seja, quando a entrada de dados de precipitação pluviométrica é do mês de fevereiro, o modelo fará a previsão da cota fluviométrica para 0 mês de abril.

Na fase de validação do Modelo de Previsão Hidrológica Xingu-Altamira, comparou-se os resultados da previsão de cota média mensal com os dados medidos, no período de 2006 a 2013 (Figura 7). Segundo Wilks (2006), a validação avalia a qualidade das previsões definida pelo grau de similaridade entre as observações e previsões. Para Collischonn (2001), no desenvolvimento de um modelo hidrológico deve-se incluir a avaliação do modelo nas tarefas as quais ele se destina, para verificar quanto os resultados previstos pelo modelo se aproximam da realidade observada.

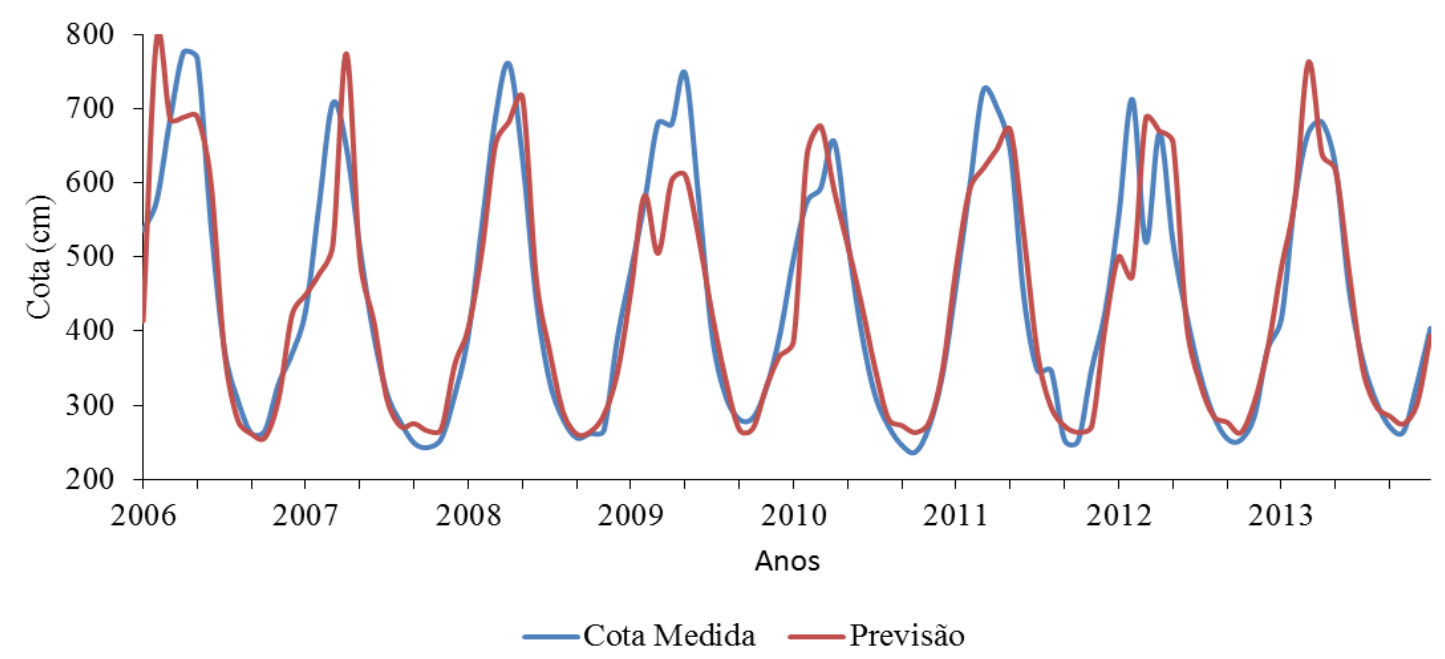

Figura 7. Cota observada e prevista para Altamira - PA (2006 a 2013)

Fonte: Própria. 
As medidas de desempenho consideradas na validação apresentaram bons resultados, com o coeficiente de Nash-Sutcliffe apresentando valor de NS = 0,83, este valor em um modelo hidrológico, para Collischonn e Tucci (2001), é considerado adequado e bom, pois o valor supera $\mathrm{NS}=0,75$. 0 coeficiente de determinação apresentou o valor de $\mathrm{r}^{2}=0,86$, segundo Moriasi et al. (2007), os valores acima de $\mathrm{r}^{2}=0,5$ são considerados como aceitáveis.

0 modelo mostra bastante coerência nos resultados, confirmados pelo coeficiente de Nash-Sutcliffe e de determinação mostrados anteriormente. 0 melhor resultado foi encontrado no ano de 2008 , com $\mathrm{r}^{2}=0,93$ e $\mathrm{NS}=0,94$ e 0 ano que apresentou resultado com menor coeficiente foi 2012, com r $^{2}=0,72$ e NS $=0,62$.

0 ano de 2012 mostra que o modelo ainda precisa de alguns ajustes, principalmente no que se refere a ocorrência de eventos extremos de precipitação na região da bacia do Xingu. Outro fator que pode causar a grande diferença entre os dados medidos e previstos são as informações inconsistentes dos dados de precipitação, que é a variável de importância no modelo. Como expõe Piscoya et al. (2013), devido a problemas de equipamento, erros do observador (falsas leituras de cotas pelo observador, erros de cópia, erro de metro, erro de complemento e leitura errônea de cotas negativas, etc.) ou problemas na alimentação no banco de dados, podem levar a inconsistência dos dados pluviométricos e fluviométricos.

\section{CONCLUSÃO}

Modelos para estimar e prever eventos hidrológicos extremos, principalmente na região amazônica, são ferramentas que auxiliam a resolução de um problema grave recorrente na Amazônia, o da baixa densidade de informação fluviométrica, tanto de cota como de vazão.

0 modelo de previsão proposto é exclusivo para a previsão fluviométrica na cidade de Altamira - PA, apresentando bom desempenho, tanto no coeficiente de Nash-Sutcliffe com 0,83 quanto no coeficiente de determinação com 0,86 .

Modelos como este são importantíssimos para entender a sazonalidade dos eventos de cheias e estiagem do rio Xingu, sendo fundamental para poder dar subsídios ao processo de tomada de decisão na cidade de Altamira - PA. 


\section{REFERÊNCIAS BIBLIOGRÁFICAS}

ANA - Agência Nacional de Águas. Hidro Web - Sistema de Informações Hidrológicas. Disponível em:

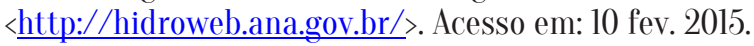

BREDA, Â. Avaliação de melhorias para um sistema de previsão hidrológica horária. 2008. 159 f. Universidade Federal do Paraná, Dissertação (Mestrado em Engenharia de Recursos Hídricos e Ambiental) - Setor Tecnológico, Curitiba, 2008.

COLLISCHONN, W. Simulação hidrológica de grandes bacias. 2001. 270 f. Universidade Federal do Rio Grande do Sul, Tese (Doutorado em Engenharia de Recursos Hídricos e Saneamento Ambiental), Porto Alegre, 2001.

COLLISCHONN, W.; TUCCI, C. E. M. Simulação hidrológica de grandes bacias. Revista Brasileira de Recursos Hídricos, v. 6 , n. 1, p. 95-118, 2001.

CRISTO, S. S. V. Análise de susceptibilidade a riscos naturais relacionados à enchentes e deslizamentos do setor leste da Bacia Hidrográfica do Rio Itacorubi, Florianópolis, Santa Catarina. 2002. 211 f. Universidade Federal de Santa Catarina, Dissertação (Mestrado em Geografia), Departamento de Geociências do Centro de Filosofia e Ciências Humanas, Florianópolis, 2002.

FRANCO, V. S. Previsão hidrológica de cheia sazonal na sub-bacia do rio Xingu e análise de vulnerabilidade social em Altamira-PA. 2014. 68 f. Universidade Federal do Pará, Dissertação (Mestrado em Ciências Ambientais), Instituto de Geociências, Belém, 2014.

IBGE - Instituto Brasileiro de Geografia e Estatística. Mapas. Disponível em: $<$ http://mapas.ibge.gov.br/>. Acesso em: 25 mar. 2015.

KAISER, I. M. Avaliação de métodos de composição de campos de precipitação para uso em modelos hidrológicos distribuídos. 2006. 400 f. Universidade de São Paulo, Tese (Doutorado em Hidráulica e Saneamento), Escola de Engenharia de São Carlos, São Paulo, 2006.

LAPP0NI, J. C. Estatística usando Excel. Rio de Janeiro: Elsevier, 2005. 476p.

MARINHO FILHO, G. M.; ANDRADE, R. S.; ZUKOWSKI JUNIOR, J. C.; MAGALHAES FILHO, L. N. L. Modelos hidrológicos: conceitos e aplicabilidades. Revista de Ciências Ambientais, v. 6, n. 2, p. 35-47, 2012.

MIRANDA NETO, J. Q. Reassentamento da população urbana diretamente afetada pelo empreendimento hidrelétrico de Belo Monte em Altamira-PA. Revista Nacional de Gerenciamento de Cidades, v. 2, n. 13, p. 43-57, 2014.

MORIASI, D. N.; ARNOLD, J. G.; VAN LIEW, M. W.; BINGNER, R L.; HARMEL, R. D.; VEITH, T. L. Model evaluation guidelines for systematic quantification of accuracy in watershed simulations. American Society of Agricultural and Biological Engineers, v. 50, n. 3, p. 885-900, 2007.

MOREIRA, I. A. Modelagem hidrológica chuva-vazão com dados de radar e pluviômetros. 2005. 96 f. Universidade Federal do Paraná, Dissertação (Mestrado em Engenharia Hidrológica) - Departamento de Hidráulica e Saneamento, Curitiba, 2005. 
Modelo de previsão fluviométrica para o rio Xingu na cidade de Altamira - PA

PEREIRA, V. R; TEIXEIRA FILH0, J. Identificação das áreas susceptíveis aos processos erosivos em duas bacias do Sistema Cantareira por meio de diferentes cenários. Acta Scientiarum Agronomy, v. 31, n. 1, p. 155-163, 2009.

PEREIRA, D. R.; MARTINEZ, M. A.; ALMEIDA, A. Q.; PRUSKI, F. F.; SILVA, D. D.; ZONTA, J. H. L. Hydrological simulation using SWAT model in headwater basin in Southeast Brazil. Engenharia Agrícola, v. 34, n. 4, p. 789-799, 2014.

PISCOYA, R.C.C.C.; LOPES, W. T. A.; LEMOS, G.M.; SILVA, L. R. S.; SILVA, M.C.A.M. Análise de consistência de dados fluviométricos de estações de monitoramento da ANA localizadas nas sub-bacias hidrográficas 10 (Rios Solimões, Javari e Itaquai) e 11 (rios Solimões, Içá e Jandiatuba). In: Simpósio Brasileiro de Recursos Hídricos, 20., 2013. Bento Gonçalves. Anais... Bento Gonçalves: ABRH, 2013. p. 1-8.

QUINTELA, A.; PORTELA, M. A modelação hidrológica em Portugal nos últimos 25 anos do século XX nas perspectivas determinística, probabilística e estocástica. Recursos Hídricos, v. 7, n. 4, p. 7-22, 2002.

RENNÓ, C. D.; SOARES, J. V. Conceitos básicos de modelagem hidrológica. Santa Maria: INPE, 2008. 59p.

SAMPAIO, F. P. R.; AGUIAR, D. G.; FILIZOLA JUNIOR, N. P.; SCHOR, T. Níveis fluviométricos e o custo de vida em cidades ribeirinhas da Amazônia: o caso de Manacapuru e Óbidos. In: Symposium Selper 2012 Earth Observation for a Green Co-Developed World, 15., 2012, Caiena. Anais... Caiena: SELPER, 2012. p. 1-9.

SANDER, C.; WANKLER, F. L.; EVANGELISTA, R. A. 0.; MORAGA, C. E. M.; TEIXEIRA, J. F. S. Cheias do rio Branco e eventos de inundação na cidade de Boa Vista, Roraima. Acta Geográfica, v. 6, n. 12, p. 41-57, 2012.

SILVA, C. A; MOREIRA, R. P.; HERRERA, J. A. Usina hidrelétrica de Belo Monte: o processo de des-reterritorialização na (i)mobilidade em Altamira/PA. In: Congresso Brasileiro de Geógrafos, 7., 2014. Vitória. Anais... Vitória: AGB, 2014. p. $1-10$.

TUCCI, C. E. M. Modelos hidrológicos. Porto Alegre: ABRH/UFRGS, 2005. 669 p.

USGS - United States Geological Survey. Shuttle Radar Topography Mission (SRTM). 〈http://earthexplorer.usgs.gov/ >. 15 abr. 2015.

VILLAS-BÔAS, A. (0rg). De olho na bacia do Xingu. São Paulo: Instituto Socioambiental. 2012. 61 p.

WILKS, D. S. Statistical methods in the atmospheric sciences. San Diego: Academic Press, 2006. 627p.

WALTER, M. T.; WALTER M. F.; BROOKS E. S.; STEENHUIS T. S.; BOLL, J.; WEILER, K. R. Hydrologically sensitive areas: variable source area hydrology implications for water quality risk assessment. Journal of Soil Water Conservation, v. 55, n. 3, p. 277-284, 2000. 